\title{
PACTO DE GESTÃO NA SAÚDE Até onde esperar uma "regionalização solidária e cooperativa?
}

\section{José Angelo Machado}

Neste trabalho lidamos com o problema da disposição de agentes governamentais para cooperar no desenvolvimento de políticas públicas que requerem o compartilhamento de ações para a realização dos seus objetivos. Instituído há vinte anos, o Sistema Único de Saúde - SUS oferece um rico e vasto campo de reflexão nesse sentido, na medida em que a montagem de redes regionalizadas e hierarquizadas de atenção - necessárias à garantia do atendimento equânime e integral a todos os cidadãos brasileiros - supõe a articulação entre municípios "exportadores" e "importadores" de serviços, sob a coordenação dos governos estaduais.

Entretanto a disposição dos agentes governamentais para cooperar entre si, na realização de tal articulação, está longe de ser uma questão trivial, tendo sido objeto de normas ministeriais que fi-

Artigo recebido em outubro/2007

Aprovado em maio/2009 xaram incentivos para organizar meios ou ofertar serviços de abrangência supramunicipal e, gradativamente, estabeleceram a regionalização como estratégia para articulação entre sistemas municipais de saúde.

Nesse particular, o Pacto de Gestão - estratégia instituída no ano de 2006, após intensas e demoradas negociações entre Ministério da Saúde e representações nacionais dos gestores estaduais e municipais - introduziu mudanças nas regras instituídas em 2002, por meio da Norma Operacional de Atenção à Saúde (NOAS), com objetivo de organizar a regionalização da atenção à saúde e estabelecer parâmetros para a firmação de um pacto intergovernamental. Uma das marcas do Pacto de Gestão, nesse sentido, é o propósito de promover uma regionalização solidária e cooperativa, adjetivação curiosamente recorrente no texto da Portaria Ministerial que o regulamentou. 
A projeção de tal propósito no futuro implica um reconhecimento tácito das dificuldades de realizar o empreendimento no presente, algo, como já dito, absolutamente necessário à articulação das redes regionalizadas de atenção à saúde. Dificuldades essas que, por sua vez, são corroboradas por fontes ligadas às três esferas de governo, por indícios documentais relevantes e, mesmo, por alguns dados preliminares, ${ }^{1}$ sugerindo a necessidade de uma agenda de pesquisa que permita delimitar precisamente os problemas e os obstáculos a serem removidos para o desenvolvimento das esperadas condutas cooperativas e solidárias entre agentes governamentais. Chama-se atenção para o fato de que, nesse sentido, não se trata de uma agenda setorial, mas sim de interesse de todas aquelas políticas públicas expostas a dificuldades de introduzir cooperação em contextos interativos imersos em dilemas de ação coletiva.

Diante desse quadro, nosso objetivo é proceder a um exercício prospectivo acerca das possibilidades de sucesso do Pacto de Gestão no alcance da almejada regionalização solidária e cooperativa, tomando por base uma avaliação crítica acerca dos efeitos produzidos pelas regras precedentes para a firmação do pacto regional. Assim, dividimos o presente trabalho em cinco segmentos. No primeiro, abordaremos a formação de redes assistenciais regionalizadas como solução para superar a fragmentação da gestão no sentido de preservar objetivos estabelecidos para o SUS. No segundo, apresentaremos referências da literatura, bem como indicações e evidências disponíveis, ainda que parciais, sobre problemas pertinentes à articulação intergovernamental para composição dessas mesmas redes. No terceiro, apresentamos uma avaliação de fatores endógenos e exógenos, pertinentes ao funcionamento das regras para o pacto intergovernamental sob a NOAS, bem como de seus efeitos. No quarto, considerando as alterações introduzidas pelo Pacto de Gestão, refletimos sobre as possibilidades de lograr a regionalização solidária e cooperativa. Por fim, no quinto e último segmento, estendemos nossas reflexões às condições para a disposição solidária em contextos institucionais mais amplos, como contribuição para pensar teoricamente o problema aqui apresentado sob os contornos particulares de uma política setorial.

\section{Regionalização e integração da rede assistencial}

Aprovado ao final do primeiro mandato do presidente Lula, ainda que gestado desde seu primeiro ano, o Pacto de Gestão alimentou-se de críticas e reflexões sobre a dinâmica das relações intergovernamentais estabelecidas na implantação da Norma Operacional de Assistência à Saúde 01/2002. Essa última Norma, diferente das anteriores, assumiu explicitamente a regionalização como macroestratégia para realizar os objetivos finais estabelecidos constitucionalmente para o SUS.

Prevista no texto da Constituição de 1988 e da Lei 8.080/90, a regionalização havia sido praticamente abandonada nos anos de 1990, quando a descentralização da gestão no setor saúde foi marcada pela transferência vertical de responsabilidades e recursos do Ministério da Saúde para os municípios. Estes passaram, então, a gerir seus sistemas locais de forma auto-suficiente, levando à fragmentação decisória e a disputas predatórias por recursos escassos, ao mesmo tempo em que era esvaziado o papel de coordenação e as competências técnicas acumuladas por anos na esfera estadual. Com a NOAS 01/2002, a regionalização foi retomada na esperança de oferecer meios para integrar sistemas municipais de saúde, agora sob a coordenação dos gestores estaduais, superando barreiras e diferenciais de acesso entre cidadãos de diferentes localidades, ou seja, a segmentação no exercício do direito à saúde de ordem geográfica. ${ }^{2}$

A integração dos serviços pertencentes a municípios de uma região de saúde, entretanto, não atendeu apenas a requisitos de otimização da capacidade instalada para ofertar procedimentos de maior complexidade. O setor de saúde apresenta características peculiares que potencializam interferências recíprocas entre políticas locais, o que pode ser percebido em pelo menos dois dos efeitos possíveis neste sentido.

O primeiro refere-se ao modo como oscilações importantes na oferta de serviços de saúde em uma jurisdição local afetam diretamente oportunidades de acesso para os cidadãos de outras localidades adjacentes. Dado o caráter efêmero do consumo de serviços assistenciais, uma vez que sejam 
dotados de mobilidade, cidadãos podem, em tese, transitar para jurisdições que ofereçam melhores oportunidades de acesso, usufruindo de benefícios públicos sem que tenham que, necessariamente, ali residir ou contrair obrigações contributivas. Mas, considerada a natureza "congestionável"3 dos bens públicos de saúde, deve-se observar que o ingresso de pacientes "externos" nos serviços de determinada localidade reduz, a partir de determinado limiar, probabilidades de pronto acesso para sua própria população. Por conseqüência, sob um regime universal de acesso - em que o atendimento não possa ser negado a qualquer necessitado, independentemente de residência - decisões locais para ampliar ou restringir oferta de serviços não afetam apenas a população da sua jurisdição, incluindo grupos residentes em outras localidades, uma vez dotados de mobilidade a ponto de se constituírem como potenciais demandantes.

O segundo efeito refere-se às repercussões que a incorporação de determinados fatores de produção por uma jurisdição local - seja de segmentos de força de trabalho especializados, seja recursos tecnológicos com baixos níveis de oferta no mercado - provoca sobre outras, na medida em que afeta as possibilidades de que também consigam fazê-lo, estabelecendo uma relação concorrencial tendente ao um jogo soma-zero.

Ora, se agregarmos à constatação dessas interferências recíprocas ou spillovers (OATES, 1999) a premissa de que relações de consumo de bens públicos afetam possibilidades de sucesso eleitoral de dirigentes locais, pode-se admitir que as primeiras venham perturbar o cálculo eleitoral dos gestores locais envolvidas na origem ou no destino dos pacientes, contaminando as relações horizontais entre os mesmos. Neste contexto, a geração de padrões de comportamento defensivos ou paranóicos, em que cada um busca se antecipar às escolhas presumidamente desfavoráveis oriundas dos outros, não deixa de ser um resultado previsível e, nesse sentido, até mesmo esperado. Desse ponto de vista, o caráter predatório e fragmentador das relações entre governos locais na década de 1990, no setor, pode ser considerado resultante das antecipações estratégicas de gestores locais ante a forte interdependência entre os sistemas municipais de saúde.
A regionalização assistencial proposta pela NOAS 01/2002 deveria inverter essa lógica, integrando sistemas locais por meio de pactos, pelos quais gestores municipais firmariam compromissos de modo que pólos regionais ou "exportadores" de serviços atendam usuários encaminhados pelos referenciados ou "importadores", institucionalizando uma rede assistencial hierarquizada na qual qualquer cidadão, independentemente de vinculação jurisdicional, tenha acesso assegurado ao atendimento em todos os níveis de complexidade.

\section{Problemas de cooperação: indicações e sugestões}

Em termos nacionais, o acesso universal, igualitário e integral à saúde abrange uma população de quase 190 milhões de brasileiros distribuídos em mais de 5.560 municípios, dos quais cerca de 4 mil têm menos de 20 mil habitantes, aproximadamente 1.300 têm entre 20 e 100 mil habitantes e 230 têm mais de 100 mil habitantes.

A contenção do ímpeto dispersivo, típico sob a protegida autonomia político-administrativa dos entes federados, e a convergência na implantação de determinados programas e políticas de saúde estratégicos, especialmente por meio da adesão às normas ministeriais e incentivos financeiros federais, são destacados na literatura pertinente como conquistas importantes da engenharia institucional do setor (Arretche, 1999, 2003; Abrúcio, 2005). O aumento da cobertura das atividades relacionadas com programas estruturantes na atenção básica - como o Programa de Agentes Comunitários de Saúde e o Programa de Saúde da Família - é um dos exemplos mais eloqüentes desse sucesso. A força do desenho institucional dos incentivos implicados estaria na estruturação de condições para que o cálculo de custos e benefícios inerente à implantação de tais programas, por parte dos gestores locais (também aqui admitidos como interessados no sucesso eleitoral), seja de tal ordem que os primeiros sejam superados pelos últimos (Arretche, 1999).

Quanto à constituição de redes assistenciais regionalizadas, sob marcos normativos estabelecidos pela NOAS $01 / 2002$, esperava-se resultados 
semelhantes, em particular que os instrumentos de gestão propostos fossem suficientes para reequilibrar o funcionamento do sistema, garantindo integralidade e eqüidade no acesso de cidadãos brasileiros oriundos de diferentes municipalidades. Os Planos Diretores de Regionalização (PDR) recortariam os territórios estaduais em módulos assistenciais, ${ }^{4}$ agregados em microrregiões e, estas últimas, em regiões, com respectivos e crescentes níveis de auto-suficiência em média e alta complexidade. A Programação Pactuada e Integrada (PPI) alocaria os recursos correspondentes de forma transparente em cada município-sede de módulo ou pólo regional de referência, estabelecendo claramente os limites físicos e financeiros para o atendimento à população própria e às populações dos municípios referenciados. Por fim, os Planos Diretores de Investimentos (PDI) mapeariam eventuais "vazios de oferta", orientando investimentos de curto, médio e longo prazo para suprir carências de oferta na capacidade instalada da rede regional. É verdade que grande maioria dos estados brasileiros avançou na concretização desses instrumentos.

A Tabela 1 apresenta a evolução do processo de habilitação de estados e municípios pela NOAS 01/2002 no período de 2002 a 2005. Deve-se ressaltar que, uma vez implantada em uma unidade da federação, o pacto regional incluía também os municípios habilitados anteriormente pela Norma Operacional Básica 01/1996, o que significa dizer que sua implantação em 2005 era amplamente majoritária no país, uma vez abrangendo 24 unidades da federação.

Tabela 1

Habilitação de Estados e Municípios Brasileiros pela NOAS 01/2002 em 2002 e 2005

\begin{tabular}{lcc}
\hline Condição & 2002 & 2005* $^{*}$ \\
\hline Estados habilitados & 14 & 24 \\
Municípios GPSM & 77 & 239 \\
Municípios GPAB-A & 134 & $1.397^{5}$ \\
\hline
\end{tabular}

* Dados referentes a janeiro de 2005.

Fonte: Brasil/Ministério da Saúde (2005b).

Entretanto a negociação e a execução dos pactos intermunicipais se mostraram bem mais complexas que o inicialmente imaginado. Nesse sentido julgamos útil a apresentação de algumas indicações e sugestões significativas - pela sua origem ou pelas circunstâncias em que foram geradas - para avaliação do sucesso dos incentivos para a regionalização assistencial, considerando três dos objetivos centrais do SUS: universalidade, igualdade e integralidade. ${ }^{6}$

\section{Universalidade}

O conjunto normativo que estabeleceu os parâmetros da firmação do pacto regional sob a NOAS 01/2002 incorporou o imperativo do acesso universal e, daí, a intolerância diante da manutenção de barreiras de acesso entre municípios, disponibilizando instrumentos para programar e incentivar o cumprimento dos pactos firmados entre "exportadores" e "importadores" de serviços. Para tanto, o referenciamento de usuários dos últimos para os primeiros seria acompanhado da correspondente alocação de recursos para o atendimento à população "de fora", eliminando, em tese, a motivação para as referidas restrições de acesso. Do mesmo modo, cessariam razões para que os últimos adotassem comportamentos predatórios como "despejar pacientes" nos primeiros.

A NOAS 01/2002 previa, inclusive, sanções negativas para constranger eventuais violações dos pactos, variando da perda de habilitação do município a alguma condição de gestão ${ }^{7}$ conquistada até a realocação de recursos destinados ao atendimento da população referenciada em outro município de referência.

Do ponto de vista dos resultados alcançados, em diversas unidades da Federação os pactos intermunicipais conviveram com tensões - ora latentes, ora manifestas - aplacadas na dependência da maior ou menor vigilância exercida pelas CIB. ${ }^{8}$ Entretanto consolidou-se, gradativamente, a percepção de que a alocação prévia dos recursos para atendimento à população referenciada em procedimentos de média e alta complexidade, nos municípios de referência, não teria sido condição suficiente para que motivações solidárias superassem condutas autointeressadas dos pactuantes. Nesse sentido, Queiroz entendeu que a NOAS permitiu visualizar que os conflitos na organização dos sistemas regionais de saúde não estavam restritos à fase de formulação, 
persistindo "dificuldades para promover a articulação entre os entes federativos, implantar instrumentos de cooperação e estabelecer regiões de saúde capazes de superar o isolamento político e institucional da quase totalidade dos municípios do país" (2004, p. 34).

Não obstante tais dificuldades, porém, a estratégia de impor barreiras de acesso foi gradativamente mitigada. Apresentando alta visibilidade quanto mais se considerado o recebimento de recursos previstos para atender municípios referenciados -, impunha um alto custo àqueles que por ela optassem. Considerado este aspecto, nossa hipótese é de que tenha havido um deslocamento das tensões e dos conflitos entre "importadores" e "exportadores" de serviços para outro campo menos visível: o da equalização das oportunidades de acesso aos serviços de referência (média e alta complexidade).

\section{Igualdade}

Em se tratando da igualdade de acesso, as condições de vigilância sobre o cumprimento dos pactos são bem mais precárias que para o caso da universalidade. Uma coisa é lidar com um imperativo categórico ou proibitivo dirigido a um segmento populacional, como os "de fora", tal como se manifesta nas barreiras de acesso. Outra, menos explícita e diluída nas relações individualizadas "caso a caso", é identificar diferenciais entre probabilidades de acesso para indivíduos pertencentes a diferentes segmentos, quanto mais consideradas limitações técnicas e políticas na regulação do cumprimento dos pactos, ${ }^{9}$ bem como o controle assimétrico sobre os meios de produção em serviços de referência e, daí, sobre portas de acesso e sobre a informação relacionada.

Sob tais condições, a violação intencional da igualdade de acesso a serviços de referência entre a população que reside no próprio município, onde são sediados, e a referenciada (ou “externa") permanece obscura para grande parte dos agentes governamentais implicados. Por conseqüência, mesmo quando sabem que pactos são violados, municípios referenciados sabem pouco à respeito das proporções desse tratamento desigual, bem como dispõem individualmente de poucos recursos para corrigi-lo. Ademais, mesmo se supridas as referidas limitações técnicas e políticas, permanecem "zonas cinzentas" (como serviços de urgência, ${ }^{10}$ por exemplo) sobre as quais o controle do cumprimento dos pactos é inerentemente limitado, dando margem para manobras no sentido de forçar o acesso de cidadãos de municípios referenciados para níveis acima do pactuado, como estratégia compensatória dos municípios "importadores".

Corroborando essa suposição acerca dos resultados do pacto regional, sob a NOAS 01/2002, há indicações e sugestões relevantes em documentos governamentais, oficiais ou não, bem como em artigos e declarações de agentes significativas para este processo, ainda que difusas. A persistência de tratamento desigual entre populações próprias e referenciadas no âmbito do SUS é admitida por dirigentes nacionais dos gestores municipais de saúde em mais de uma gestão do Conasems ${ }^{11}$ (Andrade, 2004; Machado, 2007). Registros de debates entre representações nacionais das três esferas de governo por ocasião da formulação da proposta técnica do Pacto de Gestão (Brasil/Ministério da Saúde, 2005a) também confirmam a clara percepção de iniqüidades de acesso entre municípios, pequenas e grandes regiões e estados, bem como apontam a necessidade de estabelecer sanções àqueles que não cumprem os pactos (Conass, 2004). No Relatório Final da XII Conferência Nacional de Saúde foi aprovada, inclusive, a proposta de "garantir a autonomia dos municípios na repactuação de suas referências, quando o município de referência não atender aos termos do pacto [...]" (Brasil/Ministério da Saúde, 2004, p. 69).

Do ponto de vista da necessidade de validação empírica dessa percepção, há grandes limitações para mensuração dos diferenciais de acesso entre populações próprias e referenciadas por motivos diversos, entre eles o fato de que sistemas de informação do SUS não registram residência de pacientes atendidos em procedimentos de média complexidade ambulatorial, de longe os mais executados nas referências intermunicipais. Por outro lado, mesmo para os níveis de complexidade em que essa informação é disponível - média complexidade hospitalar e alta complexidade ambulatorial 
e hospitalar - há obstáculos ao cruzamento de informações entre procedimentos executados e tetos físicos e financeiros pactuados, visto que estes últimos se valem de diferentes sistemas de informação utilizados para cálculo e registro desses tetos em cada unidade da federação. Há, portanto, necessidade de que este aspecto seja incluído numa agenda futura de investigação quanto à disposição cooperativa de agentes governamentais envolvidos nos pactos regionalizados. ${ }^{12}$

\section{Integralidade}

Por inferência, se houve tratamento desigual entre populações próprias e referenciadas quanto às condições de acesso aos serviços que compõem a atenção de média e alta complexidade assistencial, não se pode concluir outra coisa que não a presença de restrições à integralidade do acesso assistencial às últimas. Estas, com menos probabilidade de ser atendidas em algum segmento de procedimentos que as primeiras, certamente não estariam de pleno gozo do acesso a um "nível de complexidade exigido segundo suas necessidades de saúde" como preconizado no já citado artigo $7^{\circ}$ da Lei 8.080/90.

Dependendo do funcionamento harmônico e coordenado dos pactos firmados entre municípios "exportadores" e "importadores" de serviços, os problemas relacionados com a realização da integralidade de acesso também foram objeto de considerações no Relatório Final da XII Conferência Nacional de Saúde:

Para que o SUS possa ser efetivo quanto à integração e à coordenação das ações, visando a tão almejada integralidade da atenção, torna-se imperativo promover a efetiva cooperação entre as três esferas de governo, assentada em bases jurídicas sólidas, que definam claramente os papéis e responsabilidades comuns e específicas de cada ente, que potencializem os recursos financeiros e integrem a formulação de políticas, de planejamento e coordenação e de avaliação do sistema, incluindo os mecanismos de interação e de co-gestão para lidar com conflitos (Brasil/Ministério da Saúde, 2004, p. 67).
Assim, a hipótese de violação da integralidade do acesso sob as regras de firmação do pacto regional instituídas pela NOAS também se apresenta como consistente com as mesmas indicações e sugestões apresentadas, até aqui, incluindo aquelas ainda carentes de validação empírica de caráter conclusivo. $^{13}$

\section{Regras e efeitos para o pacto regional segundo a NOAS}

Tomando como referência a fragmentação da gestão dos sistemas de saúde promovida pela descentralização dos anos de 1990, marcada por condutas autodefensivas e segregantes, não se pode negar que os pactos introduzidos pela NOAS 01/2002 tenham acumulado ganhos substantivos de cooperação e coordenação. Não questionamos, neste trabalho, o avanço proporcionado pela formalização de pactos visando ao funcionamento de redes regionalizadas de referência que, antes, sequer existiam, nem mesmo o fato incontestável de que tais pactos sejam cumpridos em alguma medida. Aliás, nesse sentido, entendemos ser prudente evitar qualquer julgamento histórico que não leve em consideração o que existia antes ou no "em torno" da sua institucionalização. Mas tal prudência não pode justificar a omissão no sentido de registrar o afastamento de intenções equalizadoras ou integralizantes ou, mesmo, das próprias expectativas daqueles que conceberam as regras do pacto sob a NOAS como conducentes a relações solidárias e cooperativas entre os agentes governamentais pertinentes.

Para tanto, analisamos aqui duas ordens de fatores que integram a dinâmica do processo: de um lado, elementos endógenos - próprios às regras que presidiram o processo - e, de outro, os exógenos contendo elementos relevantes do cenário de fundo aos quais essas mesmas regras são combinadas na sua aplicação.

Quanto aos fatores endógenos, algumas implicações das regras são de relevância especial:

- Sob tais regras, municípios constituíram-se como agentes de barganha, negociando a partilha de recursos destinados à média e à alta com- 
plexidade em contrapartida à assunção de compromissos de atendimento à população do interlocutor, ainda que sob a coordenação do gestor estadual dotado de prerrogativas especiais na definição e na redefinição dos tetos financeiros. ${ }^{14}$ Configuram-se como participantes de um jogo distributivo no qual ganhos individuais são aferidos em função da eficácia na interação estratégica junto aos demais, seja como "exportador" seja como "importador" de serviços.

- Municípios "exportadores" mantiveram o controle do processo de autorização para acesso a serviços sediados em seu território ou da "porta de entrada" para eles. Detiveram, assim, posição assimetricamente vantajosa no controle sobre a execução dos pactos, tanto para sua população como para a referenciada.

- Se habilitados em GPSM, os "exportadores" gozavam da prerrogativa de gerir recursos financeiros transferidos mensalmente para atendimento à sua população própria e à referenciada. Recursos estes que, se não utilizados, incorporavam-se em definitivo ao seu teto financeiro, a despeito do seu desempenho no sentido de cumprir os pactos firmados.

Combinando tais componentes das regras de estabelecimento de pactos à premissa segundo a qual gestores municipais têm interesse em maximizar a disponibilidade de bens e serviços para seu eleitorado potencial, condutas competitivas e conflitantes poderiam ser, mais do que esperadas, até mesmo inevitáveis se admitirmos que a realização dos interesses de uns restringissem a dos interesses de outros. Os marcos institucionais regendo o pacto intergovernamental, nesse sentido, potencializariam riscos morais de que "exportadores" atentassem contra a eficiência coletiva do sistema ao agirem em benefício próprio, atuando discricionariamente no processo autorizativo em favor do acesso de sua população ou em prejuízo do acesso da população referenciada. Isso para não falar dos habilitados em GPSM, com incentivos adicionais no sentido de reter a parte dos recursos recebidos para atendimento em média e alta complexidade não utilizada, para o que naturalmente não seria razoável supor que deixasse de atender sua própria população.

Mas os efeitos produzidos pelas regras também incidiriam sobre os o cálculo dos "importadores" de serviços, oferecendo incentivos para comportamentos ineficientes do ponto de vista sistêmico. Isso na medida em que se veriam pouco estimulados a assumir custos e desgaste inerentes a investimentos na atenção básica a ponto de torná-la mais resolutiva, restringindo parte de sua própria demanda por procedimentos de média e alta complexidade em benefício indireto do "exportador". Ciente do controle assimétrico sobre o cumprimento dos pactos, seu interesse passava a ser o de transferir, o quanto possível, os encargos da assistência à saúde ao município de referência.

A barganha conflitiva, nesses termos, poderia ser representada como um jogo em dois tempos. No primeiro (ex ante), quando compromissos estão sendo firmados, "exportadores" tentam maximizar suas responsabilidades regionais a fim de captar metas para seu teto financeiro assistencial, ampliando o volume de recursos sob a sua guarda direta e, por conseqüência, suas oportunidades de retenção de resíduos. Suas ofertas teriam mais probabilidade de aceitação pelos “importadores" na medida da assimetria informacional e da dependência desigual quanto ao sucesso do acordo entre ambos. No segundo tempo (ex post), quando os pactos estão sendo executados, ambos se colocariam em posições opostas quanto ao seu cumprimento, ${ }^{15}$ dados os efeitos distributivos evidentes.

Entretanto para que possa fazer sentido, há que se considerarem fatores exógenos incidentes sobre o funcionamento de tais regras, dos quais destacamos dois de maior relevância:

- A defasagem da tabela de procedimentos do SUS, impactando negativamente como fator depreciativo dos tetos financeiros disponíveis para que "exportadores", habilitados em GPSM, executassem ou contratassem prestadores privados complementarmente para realizarem metas físicas pactuadas para atendimento de média e alta complexidade segundo valores praticados no mercado. 
- Limitações do processo de regulação do acesso assistencial $^{16}$ no sentido de assegurar simetria informacional e de controle sobre o cumprimento dos pactos, proporcionando transparência e alguma possibilidade de contenção ou freio ao poder concentrado de vigiar as "portas de acesso" e deter a guarda dos recursos financeiros pertinentes à média e à alta complexidade. O complicador é que, nos termos propostos pela NOAS, as responsabilidades regulatórias também ficaram concentradas nas mãos dos entes responsáveis pela execução dos pactos, potencializando os já mencionados riscos morais, além do que, do ponto de vista informacional, os sistemas de processamento utilizados no âmbito do SUS ainda detêm um controle precário sobre informações relativas à origem dos pacientes atendidos nos procedimentos de média e alta complexidade (Banco Mundial, 2006).

A fim de representar a combinação entre componentes das regras institucionais descritos anteriormente e fatores exógenos supracitados, vejamos o seguinte caso hipotético. Considere-se que o município M1 seja um "exportador" de serviços para M2 e M3, tendo sido habilitado para receber os recursos correspondentes ao atendimento de média e alta complexidade (GPSM). Em virtude da defasagem da tabela do SUS, o montante transferido não seria suficiente para o cumprimento das metas programadas para os três municípios, correspondendo hipoteticamente a seis unidades monetárias, ao passo que a correção da tabela do SUS por valores de mercado implicaria um repasse de oito unidades. ${ }^{17}$ Vale lembrar que essas seis unidades monetárias, transferidas ao final de cada mês para o Fundo Municipal de Saúde de M1 seriam incorporadas em definitivo ao seu teto financeiro assistencial.

Recorrendo às categorias utilizadas por Tsebelis (1998) na abordagem da barganha sob a qual agentes (ou parte deles) estão envolvidos simultaneamente em mais de uma arena, onde interage, estrategicamente, com outros agentes, poder-se-ia admitir que M1 estaria, nessas circunstâncias, dividido entre dois compromissos representados no esquema da Figura 1: de um lado, o compromisso com seu eleitorado que, num extremo, o pressiona para se apropriar de quatro das seis unidades, sob o risco de ser punido com a perda de mandato; de outro, compromisso com a região de saúde, assumido junto aos interlocutores do pacto, que o pressionam para destinar, a M2 e M3, quatro das seis unidades monetárias repassadas.

\section{Figura 1}

O Dilema de M1 diante da Defasagem do Teto Financeiro de MAC para Atender aos Compromissos Pactuados com M2 e M3

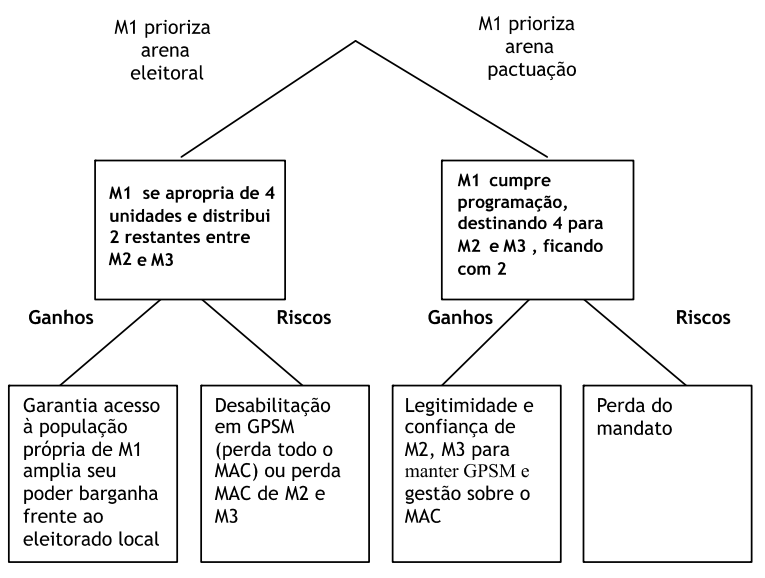

Supondo que M1 priorize o compromisso pactuado na PPI, ofertando procedimentos correspondentes a quatro unidades monetárias para M2 e M3 e assumindo o déficit das transferências, esse município se sujeitaria a tensões na arena eleitoral, seja em decorrência do déficit de acesso de sua população própria ou de sua cobertura com recursos orçamentários próprios, para o que teria que remanejá-los de outras áreas de governo (perdedoras). Mas, considerando deter o controle de acesso nos serviços de referência, poderia privilegiar, num segundo momento, seus compromissos eleitorais de modo a garantir à sua população o acesso a quatro unidades monetárias, o que certamente não seria um resultado estável, uma vez que poderia levar M1 à perda de sua habilitação em GPSM ou à redução de seu teto financeiro no que toca ao atendimento de M2 e M3 na média e alta complexidade. 
Figura 2

Efeitos da Escolha de M1 entre

Compromissos Pactuados na PPI junto a M2 e M3 e Compromissos Eleitorais em Duas Rodadas

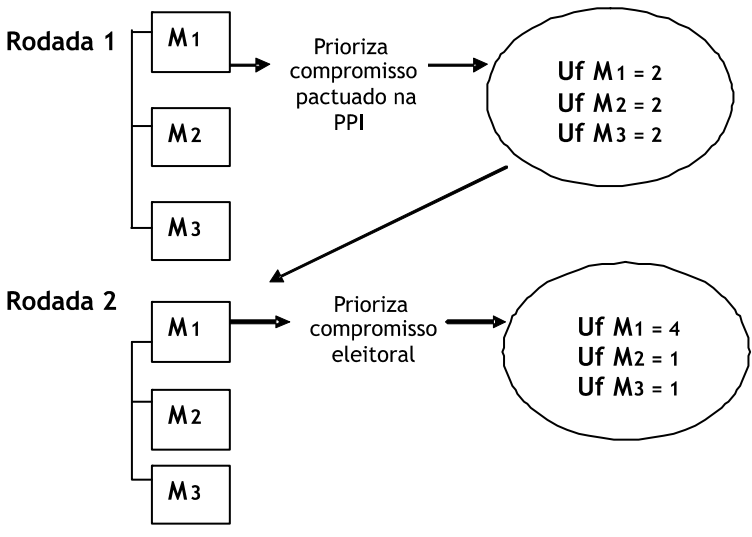

Porém, há que se destacar que a estratégia de priorizar a arena eleitoral se tornará atraente na medida em que o aparato para enforcement dos pactos regionais se mostre precário - incluindo aí assimetria informacional e baixa visibilidade na execução da programação pactuada, problemas relacionados com a regulação do acesso assistencial e constrangimentos políticos para punição de transgressores - e não o coloque sob o risco de perder suas prerrogativas conquistadas junto ao SUS.

Sob tais parâmetros relacionais, a convergência entre indicações e sugestões acerca da persistência em desigualdades de acesso, apresentada na segunda seção, sugere que a mudança no padrão de relações intergovernamentais, a ponto de promover cooperação e solidariedade entre os pactuantes, não se realizou ou só o foi de maneira incompleta. Mais do que isto: sob as mencionadas condições exógenas, as regras estimularam a luta distributiva entre as partes, tornando sua superação problemática uma vez que a negociação entre elas esbarrava em problemas de credibilidade de compromissos. Sujeitas simultaneamente a dois jogos alinhados - o jogo de barganha nas relações intergovernamentais e o jogo do sucesso eleitoral em cada município ${ }^{18}$ ambas se curvaram à tentação de privilegiar seus ganhos eleitorais, especialmente na medida em que se reconhecem como submetidos a incentivos para competição e sob frágeis instrumentos de controle, minimizando os riscos inerentes a esta escolha, como os descritos na Figura 1.

Considerando o tensionamento entre as duas arenas, portanto, não se pode entender outra coisa, senão que a construção de cooperação ou solidariedade entre entes governamentais - municipais ou pertencentes a diferentes esferas - é condicional, não podendo ser tomada como abstraída de considerações estratégicas acerca dos resultados que opções existentes produzem para cada um, de modo análogo, em outras circunstâncias sociais, à suspensão de adesão dos agentes a normas de orientação altruísta e assunção de orientações egoístas ou cínicas (Reis e Castro, 2001).

\section{Perspectivas de cooperação e a solidariedade no Pacto de Gestão}

Dado que a superposição entre arena eleitoral e arena de firmação de pacto intergestores é condição inarredável, até onde supor que mudanças nas regras instituídas pelo Pacto de Gestão sejam suficientes para modificar padrões de relacionamento governamental, no sentido de torná-los mais cooperativos on solidários?

Preliminarmente deve-se registrar que, no ocaso da NOAS e no calor das discussões para revisão da política de regionalização do SUS, já em 2003, o necessário estabelecimento de relações solidárias e cooperativas entre os entes governamentais envolvidos foi um dos temas recorrentes. Em diversos posicionamentos formalizados pelas representações de secretários estaduais (Conass, 2004) e municipais (Conasems apud Conass, 2004) ou em documentos que circularam no Ministério da Saúde (Brasil/Ministério da Saúde, 2005a), percebe-se uma rara convergência discursiva em torno da questão, notadamente incorporada ao próprio texto da Portaria GM 399 / 2006 - que institui o Pacto de Gestão -, em que o termo "solidário" e seus derivados aparecem mais de uma dezena de vezes.

Precisamente, ao definir as responsabilidades dos entes municipais no processo de regionalização, a referida Portaria contém menções, tecnicamente redundantes, ao tema: “Todo município deve: [...] Contribuir para a constituição e fortalecimento 
do processo de regionalização solidária e cooperativa, assumindo os compromissos pactuados" (Brasił/Ministério da Saúde, 2006).

Entretanto, do ponto de vista prático deve-se ressaltar que o Pacto de Gestão manteve os principais instrumentos utilizados pela NOAS 01/2002: PdOR, PPI e PDI, além do reconhecimento estratégico da função de regulação do acesso assistencial bem como da necessidade de montar unidades de trabalho (complexos reguladores) que possam executá-la adequadamente. Não obstante agregou elementos importantes às regras do pacto regional:

1. Flexibilização do desenho da regionalização assistencial no âmbito de cada unidade da federação, extinguindo os módulos assistenciais "unicêntricos" instituídos pela NOAS 01/2002 e deixando por conta de cada uma o estabelecimento do critério fundamental para definir os limites geográficos das regiões e macrorregiões de saúde (ou o "ponto de corte" entre o conjunto dos procedimentos de média complexidade que são incorporadas a uma e outra), além de admitir formalmente a abrangência interestadual ou fronteiriça (municípios limítrofes em países vizinhos) de algumas regiões.

2. Criação dos Colegiados de Gestão Regional como espaço decisório e de firmação de pacto de base regional, agora incluindo também formalmente todos os municípios abrangidos e representantes do gestor estadual, responsável pelo planejamento e definição de prioridades regionais.

3. Extinção das habilitações de estados e municípios em condições de gestão com prerrogativas previamente definidas (como a GPSM), sendo os compromissos assumidos no processo formalizados nos Termos de Compromisso de Gestão (TCG) aprovados nos respectivos Conselhos de Saúde e revistos anualmente.

4. Atribuição da responsabilidade da regulação das referências intermunicipais ao gestor estadual, que se relacionaria com centrais municipais de regulação, por sua vez ainda detentoras do controle de acesso aos prestadores nos municípios "exportadores", quando estes últimos forem gestores da média e alta complexidade. ${ }^{19}$
Admite-se, ainda, a possibilidade de co-gestão (facultativa) dos complexos reguladores incluindo, além do município sede dos serviços de referência, os demais municípios da região e representação do gestor estadual.

Em que pese outras medidas no sentido de aperfeiçoar ou tornar mais eficazes alguns instrumentos de gestão utilizados pelos gestores do SUS revisão das orientações para elaboração dos planos de saúde, programação anual de ações e relatórios de gestão; ajustes de fluxos, periodicidade e orientações para elaboração da PPI; criação de blocos de financiamento para simplificar transferências federais e outras - parece problemático que as três linhas gerais das regras descritas acima para a NOAS 01/2002 tenham permanecido praticamente intocadas. "Exportadores" e "importadores" ainda barganham referências regionais, estabelecendo partilha de recursos e responsabilidades, com efeitos distributivos; "exportadores" controlam acesso e, portanto, o cumprimento dos pactos; “exportadores" com gestão sobre a média e alta complexidade (MAC) ficam com resíduos de recursos não utilizados nos respectivos fundos municipais de saúde.

Do ponto de vista dos fatores exógenos, identificados na seção anterior com relação à NOAS 01/2002 - defasagem dos parâmetros financeiros da tabela do SUS e, por conseqüência, dos tetos financeiros destinados à média e à alta complexidade, e assimetrias na regulação do acesso assistencial -, apenas nesse último aspecto, como se pode ver no quarto item das novas regras do Pacto de Gestão relacionado acima, apresentou mudança mais significativa.

Assim, ainda que o Pacto de Gestão confira mais realismo e flexibilidade a determinados instrumentos, além de admitir maior participação dos diretamente interessados na formulação e no controle dos pactos, há elementos de continuidade significativos na predisposição de um ambiente de relações intergovernamentais permeado por conflitos e ações não cooperativas. Esses traços tenderiam a se perpetuar, a não ser que controles introduzidos por inovações no processo regulatório do acesso aos serviços de referência, além da concomitante 
superação de limitações políticas à aplicação de sanções aos transgressores dos pactos, possam afetar a distribuição de riscos e benefícios apresentada na Figura 1. Sem tal cenário, a hipótese aqui tomada como mais plausível é de que, sob seu desenho inicial, os ganhos trazidos pelo Pacto de Gestão não são ainda suficientes para neutralizar incentivos produzidos pela conjunção entre, de um lado, concentração de riscos morais embutida pelas regras da firmação do pacto em determinados agentes e, de outro, motivações advindas de externalidades relevantes. E, se for assim, a atribuição de credibilidade aos compromissos assumidos entre as partes em barganha poderá se manter problemática, minando expectativas recíprocas de seu cumprimento, elemento indispensável para preservar a disposição à solidariedade, aspecto mais bem desenvolvido a seguir.

\section{Instituições, regras e solidariedade}

À guisa de conclusão, apresentamos algumas poucas considerações sobre uma das questões cruciais envolvidas nas tentativas de introduzir padrões de conduta solidários em contextos interativos, retomando elementos do caso ora analisado e fazendo uso de algumas das possibilidades analíticas abertas pela public choice. Essa questão diz respeito, propriamente, ao problema de coordenação das expectativas de cooperação entre agentes que se encontram imersos no dilema da ação coletiva. ${ }^{20}$

De princípio, em contraposição à orientação pelo interesse próprio ou egoísta, pode-se tomar a solidariedade como relativa à disposição para assumir e cumprir compromissos com o outro ou com a coletividade da qual se faz parte. Considerando o contexto de uma política pública compartilhada constitucional e legalmente pelos entes da Federação, poderia ser traduzida como disposição para compromissos com os demais pactuantes ou com a coletividade de entes federados. Porém, diante dos obstáculos e incentivos institucionais pertinentes ao caso analisado, podemos nos perguntar sobre que aspectos seriam decisivos para promover uma inversão de condutas orientadas pelo auto-interesse para condutas solidárias. E, indo além: em que medida ajustes nas regras do jogo que presidem relações intergovernamentais poderiam, de fato, alterar a disposição dos agentes políticos envolvidos na implantação de políticas públicas?

A public choice endossa o pressuposto de que escolhas de estratégias em contextos interativos são, necessariamente, condicionadas às escolhas dos demais implicados (Scharpf, 1997), ou seja, que, mirando os aspectos distributivos resultantes de diferentes alternativas disponíveis, escolhe-se entre cooperar ou não "com um olho" no que o outro também vai fazer. Nesse sentido, escolhas estratégicas são, inerentemente, condicionais.

Um achado empírico interessante para ilustrar este aspecto vem da análise das condições de manutenção de disposições cívicas em determinados segmentos sociais, onde, por meio de um survey, Reis e Castro (2001) constataram o súbito deslocamento de uma ampla adesão a normas de orientação solidária ou altruísta para condutas egoístas ou cínicas, na medida em que os outros deixaram de cooperar. Os autores entendem como elementochave para produção desse efeito, portanto, a perda de eficácia da ação solidária uma vez constatada a falta de reciprocidade dos demais agentes diante de tal ação. Nessa circunstância, considerando o abandono da orientação normativa pelos demais, a esmagadora maioria dos pesquisados redefiniu sua predisposição a estabelecer e cumprir compromissos altruístas, retroagindo para uma orientação pelo auto-interesse. Em suma, constataram que na esfera dos valores cívicos, a disposição à solidariedade não é incondicional, dependendo da disposição dos demais para se orientarem pelos ditos valores.

De modo similar, o reconhecimento da perda de eficácia das ações solidárias também poderia ser tomado como elemento crucial em um contexto interativo na esfera das relações intergovernamentais, sobretudo considerando efeitos provocados sob regras institucionais específicas. Diante da constatação, por determinado agente, de que outro detém não apenas os instrumentos ou o poder, mas também motivações para agir egoisticamente, minando eventuais benefícios de uma opção pela cooperação; de que há um desnivelamento ou assimetria informacional que lhe impede de monitorar eficaz- 
mente os movimentos desse agente; de que, ao agir no próprio interesse, ele não sofrerá ou terá poucas possibilidades de sofrer sanções negativas; então é pouco provável que mantenha incondicionalmente sua adesão a normas solidárias ou altruístas. ${ }^{21}$

Promessas verbais ou formais de solidariedade, sob tais circunstâncias, com maior ou menor carga ideológica, defrontam-se com problemas de credibilidade de compromissos que, por desdobramento, obstaculizam a transposição coordenada de estratégias de deserção social por parte de agentes sociais ou políticos para situações de cooperação geral em equilíbrio. É isso que justifica, em grande medida, a insistência na adoção de medidas visando a aperfeiçoamento de regras e procedimentos institucionais para contenção do auto-interesse, tais como as que estabelecem freios e contrapesos, controles recíprocos, transparência ou aplicação de sanções aos desviantes do interesse coletivo. Tratase de, via desenho institucional, estabelecer formas de dispersão do poder ou de tornar custosa a opção por uma orientação em sentido contrário à solidariedade.

Outro aspecto é que, se tais constrangimentos institucionais não supõem mudanças no estado de coisas pela via do entendimento orientado por valores (como o altruísmo ou outros) entre os ditos agentes, por outro lado é plausível supor conduzirem a reconhecimento recíproco da sujeição à norma e às sanções, atributo necessário para "blindar" a credibilidade de compromissos assumidos da ação corrosiva exercida pela tentação de traí-los quando se dispõe de instrumentos e motivos para tanto. A sujeição a normas e sanções, embora não uma condição suficiente, coloca-se, portanto, como um requisito fundamental para a disposição dos agentes para estabelecer e cumprir acordos entre si ou em benefício da coletividade.

Disso infere-se que a instauração de relações intergovernamentais solidárias no SUS requer medidas que aprofundem o controle e o disciplinamento no exercício dos poderes concentrados sob as regras que presidem o processo de firmação do pacto regional, um equivalente do tema recorrente no pensamento político das exigências de controle do poder (Bobbio, 2001), agora não propriamente dos go-vernantes pelos governados, mas entre governantes que atuam coordenadamente em posições assimétricas e sob interesses potencialmente conflitivos no contexto federativo. É nesse sentido que mudanças de normas que presidem interações no processo de firmação do pacto regional poderão estabelecer novos parâmetros de cálculo para agentes governamentais, limitando ou compartilhando poderes antes concentrados em posições "privilegiadas" do sistema, como no "planejador central", no município que controla o processo autorizativo ou no que, além disso, gere os recursos destinados a serviços de abrangência regional.

Retomando a questão de origem deste trabalho, não obstante avanços no plano discursivo, entende-se haver um conjunto de indicações de que ainda são precárias as garantias institucionais de que a "regionalização solidária e cooperativa" seja incorporada às expectativas recíprocas dos gestores do SUS ao se orientarem na formulação e na execução dos pactos regionais. Não obstante, há indícios de mudanças que poderão ser futuramente aprofundadas no sentido de superar o atual estágio, no qual o tema da solidariedade ainda teima em se colocar como aspiração futura em cartas, agendas e resoluções conjuntas dos gestores do SUS.

\section{Notas}

1 Mobilizamos, nesse sentido, depoimentos de agentes governamentais-chave e documentos colhidos para análise (ver Machado, 2007).

2 A Norma Operacional Básica 01/1996 previa a programação intermunicipal da atenção à saúde e a alocação de recursos nas referências para atendimentos regionalizados, mas faltaram condições políticas e instrumentos de gestão que permitissem avançar de modo significativo.

3 Congested public goods são definidos por Scharpf (1997) como categoria especial de bens públicos em que o consumo por parte de alguns pode afetar a probabilidade de consumo por outros, ao contrário dos bens públicos típicos.

4 O módulo assistencial constituía a menor unidade territorial da regionalização, podendo corresponder a um grupamento de municípios, um único município de maior porte ou partes de uma metrópole, caracterizando-se pelo nível de auto-suficiência para ofertar 
todos os procedimentos padronizados pelo Ministério da Saúde como primeiro nível de média complexidade ou MC1.

5 Em 2004, a Portaria GM 2.023/2004 estendeu a responsabilidade pela gestão de atenção básica a todos os municípios brasileiros independentemente de habilitação voluntária, medida mantida no Pacto de Gestão em 2006.

6 Enquanto a universalidade e a igualdade são objetivos finalísticos que dizem respeito à relação jurídica entre cidadãos e bens públicos de saúde, a integralidade é um requisito técnico relativo à abrangência desses mesmos bens públicos: ações preventivas e curativas, individuais e coletivas, exigidas para cada caso em todos os níveis de complexidade (Brasil, Lei 8080/1990, art. $7^{\circ}$ ).

7 A NOAS 01/2002 lidou com duas condições de gestão: numa o município assumia apenas a gestão da atenção básica (Gestão Plena de Atenção Básica Ampliada ou GPAB-A), deixando a gestão da média e alta complexidade ao estado; na outra, assumia a gestão de todo o sistema municipal (Gestão Plena do Sistema Municipal ou GPSM).

8 Comissão Intergestores Bipartite, constituída no âmbito de cada estado da Federação com representação paritária dos gestores municipais e estadual para tomar decisões e operacionalizar a descentralização de responsabilidades de gestão e recursos no seu âmbito de atuação.

9 Limitações técnicas referem-se, entre outras coisas, ao inexistente ou precário funcionamento de sistemas de informação que permitam identificar pacientes encaminhados entre municípios, em tempo real ou útil, e controlar o cumprimento dos pactos. Limitações políticas referem-se, especialmente, à precariedade dos fóruns intergestores para fazer cumprir decisões coletivas, inclusive aplicando penalidades quando for o caso.

10 Nestes, uma vez não programáveis, o caráter imediato do atendimento dá margem para que o mesmo, uma vez iniciado, possa abrir caminho para exames complementares, interconsultas ou acompanhamentos, que levam pacientes a consumirem procedimentos a despeito do pactuado e de sua origem. Há relatos de gestores municipais de saúde de que essa "brecha" é muitas vezes utilizada intencionalmente para quebrar os pactos (Machado, 2007).

11 Colegiado Nacional de Secretários Municipais de Saúde.

12 Dados preliminares agregados, referentes ao período de outubro/2005 a setembro/2006 e disponibiliza- dos pela Secretaria de Estado da Saúde de Minas Gerais para consultas, via web, apontam para o fato de que, em 10 das 13 macrorregiões de saúde do estado, houve extrapolamento de tetos pactuados para as populações próprias (realizado > pactuado) e subutilização dos tetos para as populações referenciadas (realizado $<$ pactuado). Em duas delas teria havido tal extrapolamento para ambos os segmentos populacionais e, finalmente, em um, teria havido subutilização para ambos. Não se verificou nenhuma macrorregião onde o volume agregado de recursos executados excedesse os tetos pactuados para a população referenciada e onde, ao mesmo tempo, tal volume estivesse aquém do pactuado para a população própria. Esses dados corroboram a percepção descrita acima, quanto a um déficit de equalização do acesso com base na origem dos pacientes, embora não possam ser tomados como conclusivos, até mesmo porque existem relatos de estudos apresentando resultados divergentes, o que reforça ainda mais a necessidade de desdobrar mais esforços nesse sentido.

13 A mesma base de dados disponibilizada pela Secretaria de Estado da Saúde de Minas Gerais - referente ao período de outubro/2005 a setembro/2006 - indica, agora sob os dados referentes a todo o estado e não mais desagregados por macrorregião, perfis distintos para os níveis de média complexidade hospitalar em face da alta complexidade, tanto ambulatorial como hospitalar. Sobressai a elevada proporção de subutilização dos recursos pactuados para a população referenciada no caso da média complexidade hospitalar, apontando um déficit importante de acesso nesse nível de atenção.

14 Embora, por medida de simplificação, não analisamos aqui a variável "comportamento do governo estadual”, devemos admitir, desde já, que ela importa, e muito. Consistente com as proposições que iremos aqui desenvolver, é esperado que aspectos conflitivos e competitivos nas relações de barganhas entre municípios sejam mais aguçados, na medida em que os estados estejam ausentes do processo e provavelmente abrandados onde os estados exercerem mais ativamente seu papel de coordenação. De qualquer maneira, não queremos desconhecer que o estado, também, se insere como agente interessado nas contradições entre municípios em barganha, estabelecendo outra arena de barganhas e trocas que visam ao atendimento dos seus interesses próprios.

15 Exportadores de serviços esforçam-se para minimizar o consumo de seu teto financeiro para média e alta complexidade por meio do atendimento à população 
referenciada, enquanto importadores se esforçam para maximizar o consumo desse mesmo teto.

16 Essa função foi concebida com objetivo de "promover a equidade do acesso, garantindo a integralidade da assistência e permitindo ajustar a oferta assistencial disponível às necessidades imediatas do cidadão, de forma equânime, ordenada, oportuna e racional" (Brasil, 2002, p. 4).

17 Consideremos que, dessas, quatro fossem referentes à população própria de M1 e quatro seriam referentes à referenciada de $\mathrm{M} 2$ e M3, sendo duas para cada um desses últimos, considerando que a população do primeiro corresponde à somatória dos demais e que fatores adicionais de cálculo para distribuição dos recursos fossem equivalentes.

18 Trata-se de duas arenas paralelas, tal como descrito por Tsebelis (1998) na representação política, em que agentes se envolvem em dois jogos: da barganha entre lideranças (tal como ocorre na arena parlamentar) e da representação das bases pela liderança (tal como pode ocorrer na arena eleitoral ou na arena partidária).

19 Similar à antiga GPSM.

20 O dilema da ação coletiva remete ao clássico trabalho de Olson Jr. (1968), em que o autor busca responder às indagações em torno dos motivos que levariam à deserção de indivíduos ante os esforços necessários para que um grupo possa realizar um bem público para si. O dilema, propriamente, refere-se à dicotomia entre cooperar com o grupo de indivíduos racionais, portanto com bons motivos para não fazer o mesmo, ou desertar da cooperação.

21 Esse aspecto nos remete a considerações éticas no sentido de que se trata de uma orientação distinta da "ética da convicção" que, em Weber, implica agir sob o mandamento ou a norma, não importam os resultados.

\section{BIBLIOGRAFIA}

ABRUCIO, F. L. (2005), “A coordenação federativa no Brasil: a experiência do período FHC e os desafios do governo Lula". Revista de Sociologia e Política, 24: 31-67, jun., Curitiba.

ANDRADE, L. O. M. (2004), "SUS pós NOB III: o SUS de Pacto de Gestão. Brasília. Disponível no site <http://www.conasems.org.br/ mostraPagina.asp? codServico $=1280 \&$ codPagina $=1122>$. Acessado em 6 set. 2006.
ARRETCHE, M. T. S. (1999), "Políticas sociais no Brasil: descentralização em um estado federativo". Revista Brasileira de Ciências Sociais, 14 (40): n111-141, jun., São Paulo.

. (2003), "Financiamento federal e gestão local de políticas sociais: o difícil equilíbrio entre regulação, responsabilidade e autonomia". Ciência \& Saúde Coletiva, 8 (2): 331-345, Rio de janeiro.

BANCO MUNDIAL. (2006), "Avaliação dos processos de regulação assistencial, avaliação e controle no SUS: relatório consolidado". Estudo elaborado por José Angelo Machado mediante Termo de Referência firmado junto ao Ministério da Saúde. Brasília, Ministério da Saúde.

BOBBIO, Norberto. (2001), A teoria das formas de governo. Tradução de Sérgio Bath. Brasília, Editora Universidade de Brasília.

BRASIL/MINISTÉRIO DA SAÚDE. (2002), "Portaria 423, de 09 de julho de 2002". Disponível no site < http://dtr2001.saude.gov.br/sas/ PORTARIAS/PORT2002/PT-423.htm>. Acessado em 6 set. 2006.

(2004), "XII Conferência Nacional de Saúde - Conferência Sérgio Arouca: relatório final". Brasília, Ministério da Saúde.

. (2005a), "Documento base para discussão tripartite do Pacto pela Saúde: documento elaborado pelo Ministério da Saúde para discussão tripartite". Brasília, Ministério da Saúde.

(2005b), "Coordenação Geral de Integração Programática - PDR por Estado”. Disponível no site <http://dtr2001.saude. gov.br/dad/CgaIP/PDR/prd.htm>. Acessado em 22 jan.

. (2006), "Portaria 339, de 22 de fevereiro de 2006". Disponível no site <http:// dtr2001.saude.gov.br/sas/PORTARIAS / Port2004/GM/GM-339.htm>. Acessado em 6 set.

CONASS. (2004), "Relatório da Oficina "Pacto de Gestão". Disponível no site <http:// cedoc.ensp.fiocruz.br/descentralizar/anexos/ Nota $\% 20$ T\%C3\%A9cnica_CONASS_relat $\%$ C $3 \%$ B 3rio_oficina $\% 20$ pacto $\% 20$ de $\%$ 20 gest $\%$ C3\%A3o.doc $>$. Acessado em 13 set. 
MACHADO, J. A. (2007), Políticas públicas descentralizadas e problemas de coordenação: o caso do Sistema Único de Saúde. Belo Horizonte, tese de doutorado, Universidade Federal de Minas Gerais (mimeo.).

OATES, W. E. (1999), "An essay on fiscal federalism". Journal of Economic Literature, 37 (3): 11201149, Pittsburgh.

OLSON JÚNIOR, M. (1968), The logic of collective action: public goods and the theory of groups. Nova York, Schocken Books.

QUEIROZ, L. F. N. (2004), "A regionalização da assistência à saúde no Brasil: avanços e dificuldades na implantação da NOAS-SUS". Revista de Políticas Públicas e Gestão Governamental, ano 1 (1): 9-36, set., Brasília.

REIS. F. W. \& CASTRO, M. M. M. (2001), “Democracia, civismo e cinismo: um estudo empírico sobre normas e racionalidade". Revista Brasileira de Ciências Sociais, 16 (45): 25-46, fev.

SCHARPF, F. W. (1997), Games real actors play: actorcentered institucionalism in policy research. Boulder, Westview Press.

TSEBELIS, G. (1998), Jogos ocultos: escolba racional no campo da politica comparada. Tradução de Luiz Paulo Rouanet. São Paulo, Edusp. 


\section{PACTO DE GESTÃO NA SAÚDE}

\section{José Angelo Machado}

Palavras-chave: Descentralização; Coordenação intergovernamental; Regionalização; Teoria da cooperação.

Neste trabalho tratamos dos problemas de coordenação intergovernamental emergentes na formação das redes assistenciais regionalizadas e hierarquizadas, estabelecidas no âmbito do Sistema Único de Saúde (SUS), de modo a articular municípios "exportadores" e "importadores" de serviços de saúde com maior complexidade tecnológica sob a coordenação dos governos estaduais. Com base numa avaliação crítica acerca dos efeitos, produzidos pelas regras institucionais que lhe dão amparo, sobre a disposição dos agentes governamentais à cooperação, apresentamos uma reflexão prospectiva em torno das possibilidades de que o Pacto de Gestão do SUS, firmado entre as três esferas de governo no ano de 2006 e atualmente em desenvolvimento, venha a consumar a almejada regionalização solidária e cooperativa.

\section{A MANAGEMENT PACT ON HEALTH}

\section{José Ângelo Machado}

Keywords: Descentralization; InterGovern Coordination; Regionalization; Cooperation theory.

In this paper we deal with emerging inter-govern coordination problems when forming the regionalized and hierarchical assisting nets, established in the $\mathrm{Na}$ tional Health System (SUS) in a way to articulate the "export" and "import" health service municipalities with a greater technology complexity under the coordination of the state governments. Based on a critical assessment about the effect produced by the institutional rules that supports them, we present a prospective reflection about the possibilities that the Management Pact of SUS, entered among the three ranges of government in the year of 2006 and currently under development, comes to consummate the so desired understanding and cooperative regionalization.

\section{PACTE DE GESTION DANS LA} SANTÉ

\section{José Ângelo Machado}

Mots-clés: Déscentralisation; Coordination intergouvernementale; Régionalisation; Théorie de la Coopération.

Le sujet de ce travail est d'étudier les problèmes de coordination intergouvernementale qui émergent de la formation des réseaux d'assistance régionalisés et hiérarchisés, établis dans le sein du Système Unique de Santé (SUS), de façon à articuler les municipalités "exportatrices" et "importatrices" de services de santé ayant une plus grande complexité technologique, sous la coordination des gouvernements de chaque état. A partir d'une évaluation critique à propos des effets produits, des règles institutionnelles qui les sous-tendent, de la disposition des agents gouvernementaux à la coopération, nous présentons une réflexion prospective sur les possibilités que le Pacte de Gestion du SUS, accordé entre les trois sphères de gouvernement à l'an 2006, et qui se développe en ce moment, vienne à réaliser la régionalisation solidaire et coopérative souhaitée. 